TITLE:

\title{
Generation of Organozinc Reagents from Arylsulfonium Salts Using a Nickel Catalyst and Zinc Dust
}

\section{AUTHOR(S):}

Yamada, Kodai; Yanagi, Tomoyuki; Yorimitsu, Hideki

\section{CITATION:}

Yamada, Kodai ...[et al]. Generation of Organozinc Reagents from Arylsulfonium Salts Using a Nickel Catalyst and Zinc Dust. Organic Letters 2020, 22(24): 9712-9718

\section{ISSUE DATE:}

2020-12-18

URL:

http://hdl.handle.net/2433/261022

\section{RIGHT:}

This document is the Accepted Manuscript version of a Published Work that appeared in final form in Organic Letters, copyright $($ American Chemical Society after peer review and technical editing by the publisher. To access the final edited and published work see https://doi.org/10.1021/acs.orglett.0c03782.; The full-text file will be made open to the public on 10 December 2021 in accordance with publisher's 'Terms and Conditions for Self-Archiving'.; This is not the published version. Please cite only the published version.: この論文は出版社版でありません。引用の際には出版社版 をご確認じ利用ください。 


\title{
Generation of Organozinc Reagents from Arylsulfonium Salts Using a Nickel Catalyst and Zinc Dust
}

\author{
Kodai Yamada, Tomoyuki Yanagi, and Hideki Yorimitsu* \\ Department of Chemistry, Graduate School of Science, Kyoto University, Sakyo-ku, Kyoto 606-8502, Japan \\ KEYWORDS: metalation, organozinc reagents, nickel, $C-S$ cleavage, sulfonium salts.
}

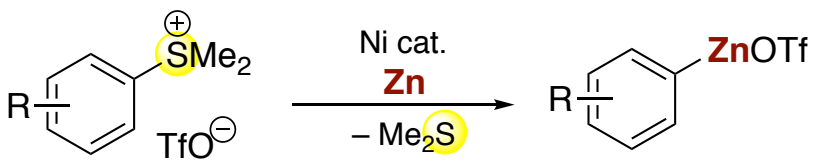

efficient catalytic $C-S$ cleavage to generate a wide range of synthetically useful arylzinc reagents under mild conditions

ABSTRACT: Readily available aryldimethylsulfonium triflates react with zinc powder under nickel catalysis via the selective cleavage of the $\mathrm{sp}^{2}$-hybridized carbon-sulfur bond to produce salt-free arylzinc triflates under mild conditions. This zincation displays superb chemoselectivity and thus represents a protocol that is complementary or orthogonal to existing methods. The generated arylzinc reagents show both high reactivity and chemoselectivity in palladium-catalyzed and copper-mediated cross-coupling reactions.

Organometallic compounds are indispensable reagents in organic synthesis. Organozinc compounds show superb reactivity and have thus been widely used in highly chemoselective crosscoupling reactions and addition reactions across unsaturated bonds. ${ }^{1}$ As the importance of organozinc reagents has increased, methods to efficiently prepare functionalized organozinc reagents under mild conditions have been diligently investigated. ${ }^{1 \mathrm{~d}, 1 \mathrm{i}, 2}$ The insertion of zinc metal into the carbon-halogen bond of an organic halide represents a promising method for the preparation of functionalized organozinc reagents. It enables the regioselectivity to be set, offers a broad scope, and is a robust method. Zinc insertion without a catalyst ${ }^{1 \mathrm{e}, 3}$ or in the presence of a stoichiometric amount of lithium chloride ${ }^{1 \mathrm{~d}, 1 \mathrm{ii}, 2,4}$ is commonly used to allow organic iodides, activated aryl bromides, and benzylic or allylic chlorides to serve as precursors for organozinc reagents. To expand the scope of zincations with respect to the organic halides that can be employed, the use of transition-metal catalysis has been investigated (Scheme 1a). Gosmini has pioneered and advanced zincation reactions using a cobalt catalyst, ${ }^{5}$ whilst Yoshikai has developed an improved method. ${ }^{6}$ Based on their combined efforts, such cobalt catalysis now accommodates aryl bromides, aryl chlorides and even phenol derivatives, i.e., aryl triflates. ${ }^{5 \mathrm{~d}}$ Very recently, Hintermann has reported the nickel(diimine)-catalyzed formation of arylzinc reagents from general aryl sulfonates. ${ }^{7}$ These catalytic methods, as well as other examples, ${ }^{8,9}$ are the basis for further highly exciting catalytic zinc-insertion reactions.

Due to their ready availability and synthetic versatility, ${ }^{10}$ organosulfur compounds hold great potential as precursors of organozinc compounds. However, the strength of the $\mathrm{C}-\mathrm{S}$ bond and the often catalytically poisonous nature of the sulfur fragments generated during the reaction render catalytic zinc- insertion reactions into $\mathrm{C}-\mathrm{S}$ bonds challenging. Although Gosmini ${ }^{11}$ and Hintermann ${ }^{7}$ have reported cobalt- and nickel-catalyzed zinc-insertion reactions into aryl sulfides, the available precursors are limited to particularly reactive (benzo)thiazoyl and naphthyl sulfides ${ }^{12}$ (Scheme $1 \mathrm{~b}$ ). This underscores the difficulties associated with achieving the S-to- $\mathrm{Zn}$ transformation. In addition, the synthetic application of these arylzinc reagents has only been investigated for trivial iodinations and a small number of Negishi coupling reactions. The utility of organosulfur compounds as precursors of organozinc reagents is thus underdeveloped.

We are interested in the development of catalytic reactions of organosulfur compounds via the cleavage of the C-S bond. ${ }^{13-15}$ Recently, we have reported the nickel-catalyzed carboxylation of arylsulfonium salts using zinc powder with carbon dioxide. ${ }^{16}$ This study implied that an arylzinc species is the intermediate formed prior to the carboxylation event, although tangible evidence for this hypothesis had been elusive ${ }^{17}$ or deemed unlikely ${ }^{18}$ in nickel-catalyzed carboxylation reactions, which use a metallic reductant. Our previous success in preparing arylboronate esters from arylsulfonium salts and bis(pinacolato)diboron $^{14 a}$ via a palladium-catalyzed reaction also encouraged us to develop another important ipso-metalation of arylsulfonium salts. With this in mind, we report here an efficient nickel-catalyzed preparation of arylzinc reagents from a variety of arylsulfonium salts (Scheme 1c).

Encouraged by Liebeskind's original idea, ${ }^{19-21}$ we prefer using arylsulfonium salts as aryl pseudohalides. When compared to neutral aryl sulfides, arylsulfonium salts have several advantages for nickel-catalyzed zinc-insertion reactions that can be explained on the basis of the possible reaction 
mechanism ${ }^{5,7,16}$ (Scheme 2): (1) Arylsulfonium salts are electron-deficient and undergo smoother oxidative addition; (2) the oxidative addition forms a cationic arylnickel intermediate that is more susceptible to reduction by metallic zinc, ${ }^{22}$ (3) instead of anionic sulfur fragments, a neutral and catalytically less poisonous sulfide is formed; (4) arylsulfonium salts, which can be readily prepared from aryl mercaptans or sulfides on a large scale, usually exhibit good crystallinity as well as bench-stability. We also had to pay attention to the possibility of the undesired degradation of the arylsulfonium salts into neutral aryl sulfides via demethylation. This could potentially occur via the action of a nucleophilic arylmetal species generated in situ or by a single-electron transfer (SET) from zinc or a low-valent nickel species. ${ }^{23}$ Suppressing the SET is also important for controlling the regioselectivity of the $\mathrm{C}-\mathrm{S}$ bond cleavage, where $\mathrm{sp}^{2} \mathrm{C}-\mathrm{S}$ bond cleavage via two-electron oxidative insertion predominates over SET-induced $\mathrm{sp}^{3} \mathrm{C}-\mathrm{S}$ bond cleavage.

Scheme 1. Catalytic Zinc-Insertion Reactions into Aryl Halides and Pseudohalides.

a) General method for the catalytic zincation of aryl halides and sulfonates

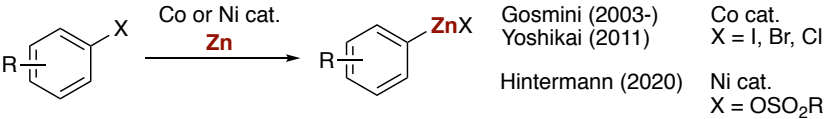

b) Scarce examples of the catalytic zincation of special aryl sulfides
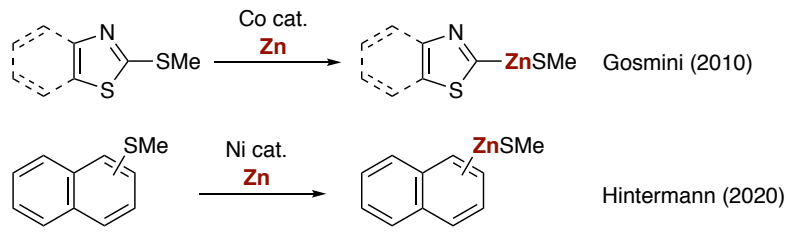

c) This work: Catalytic zincation of readily available arylsulfonium salts

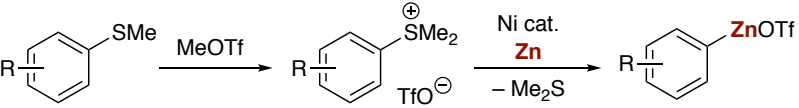

Scheme 2. Mechanistic Working Hypothesis.

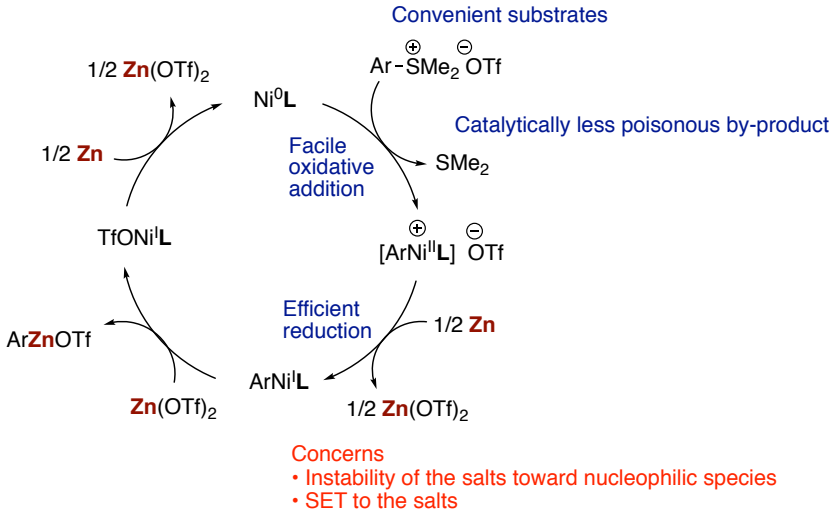

Our investigations began by evaluating the catalytic zincation of 1a (Scheme 3). The efficiency of the zincation was assessed using ${ }^{1} \mathrm{H}$ NMR spectroscopy to analyze the iodinated product 3a after iodolysis. Simply applying the standard conditions from our previous carboxylation in the absence of carbon dioxide $^{16}$ resulted in a zincation with poor reproducibility. After some experimentation, we found that the addition of $6.0 \mathrm{~mol} \%$ of a supporting ligand ensures reproducibility. Of the ligands tested, 2,9-dimethylphenanthroline (L1) proved to be the most effective. ${ }^{23}$ While monomethylated $\mathbf{L} 2$ showed comparable reactivity, neither the parent phenanthroline (L3) nor 3,4,7,8-tetramethylphenanthroline (L4) worked. The more flexible 2,2'bipyridyl ligands $\mathbf{L 5}$ and $\mathbf{L 6}$ did not facilitate the zincation. In these four runs with $\mathbf{L 3}-\mathbf{L 6}$, low conversions were observed. Finally, using $2.5 \mathrm{~mol} \%$ of the complex $\mathrm{NiBr}_{2} \mathbf{L 1}$ and an additional $10 \mathrm{~mol} \%$ of $\mathbf{L 1}$ provided $\mathbf{3 a}$ in $91 \%$ yield. A screening of solvents revealed that $N, N$-dimethylacetamide (DMA) is the best while $N$-methylpyrrolidone (NMP), dimethyl sulfoxide (DMSO), and $N, N^{\prime}$-dimethylpropyleneurea (DMPU) are almost comparable. Conversely, the zincation did not occur in other polar solvents such as acetonitrile or tetrahydrofuran (THF). $N, N$ '-dimethyl-2-imidazolidinone (DMI) and tetramethylurea (TMU) showed moderate performance. The corresponding cobalt complex $\mathrm{CoBr}_{2} \mathbf{L 1}$ was not catalytically active in the zincation. In this case, as well as in the absence of any transitionmetal complex, gradual demethylation of 1a was observed, most likely via a SET directly from the zinc powder to $1 \mathbf{a} .{ }^{24}$ The neutral sulfide $p$ - $t \mathrm{BuC}_{6} \mathrm{H}_{4} \mathrm{SMe}$ did not undergo zincation, discarding the possibility of an aryl sulfide intermediate in the zincation.

\section{Scheme 3. Optimization Study of the Zincation Reaction.}

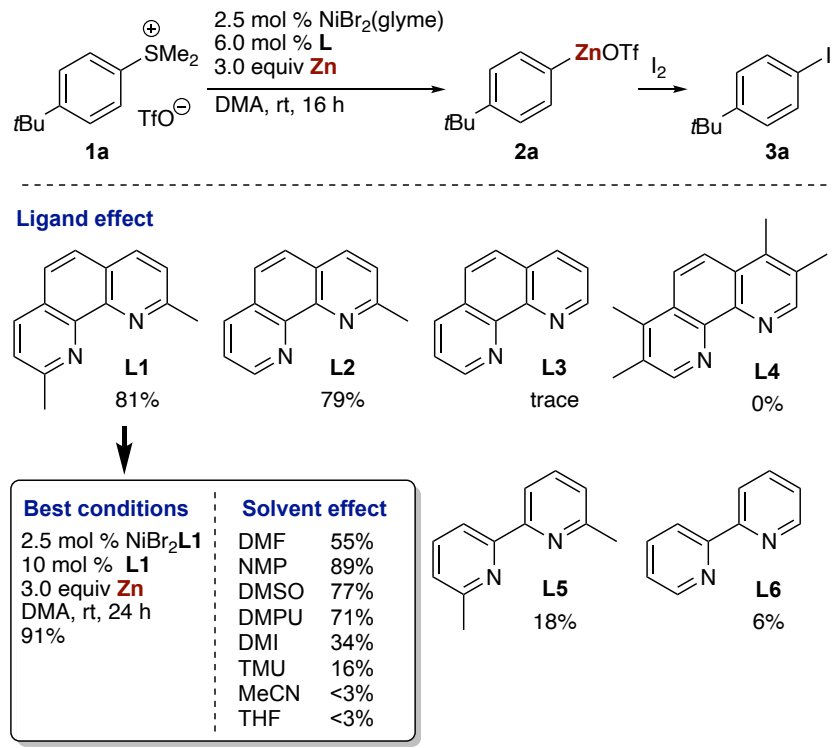

With the optimized conditions in hand, we investigated the reaction scope (Scheme 4). Electron-rich and -neutral arylsulfonium salts $\mathbf{1 a}-\mathbf{1 d}, \mathbf{1 h}$, and $\mathbf{1 i}$ displayed good reactivity. ${ }^{25}$ As expected, 1c, which contains a methylsulfanyl group, was selectively zincated at the sulfonium moiety. The methoxy group at the ortho position in $\mathbf{1 d}$ has little effect on the zinc insertion. Electron-deficient cyano-substituted 1e suffered from competitive SET from either the zinc powder or a low-valent nickel species, ${ }^{24}$ and thus demethylation of 1 e competed to yield 4-methylsulfanylbenzonitrile and the yield of $\mathbf{3 e}$ was moderate. ${ }^{26}$ Notably, the zincation of the other electron-deficient arylsulfonium salts $\mathbf{1 f}-\mathbf{1 g}$ proceeded efficiently under the standard conditions. The potentially reactive carbonyl groups in $\mathbf{3 f}-\mathbf{3 h}$ were unaffected by the reaction conditions. Surprisingly, the acidic protons in $\mathbf{1 h}$ have no detrimental effect on the reaction, and the corresponding zinc reagent $\mathbf{2 h}$ was found, after filtration, 
to be storable under an inert atmosphere at ambient temperature (vide infra). Interestingly, the potentially reactive sulfonate and chloro groups $^{5-7}$ in $\mathbf{1} \mathbf{j}-\mathbf{1 m}$ remained mostly intact and the $\mathrm{C}-\mathrm{S}$ bond cleavage proceeded selectively. Small amounts of $p$-diiodobenzene were observed in the reactions of $\mathbf{1} \mathbf{j}-\mathbf{1 1}$, whilst no $\mathrm{m}$ diiodobenzene was detected in the reaction of $\mathbf{1 m}$. The zincation tolerated a pinacolatoboryl group, thus providing ample scope for further derivatization via orthogonal Suzuki-Miyaura cross-coupling reactions. Zincation in 10 occurred predominately at the $\mathrm{sp}^{2} \mathrm{C}-\mathrm{S}$ bond rather than at the $\mathrm{sp}^{3} \mathrm{C}-\mathrm{Cl}$ bond to yield 3o' after hydrolysis with $\mathrm{D}_{2} \mathrm{O}$. The bromo group in $\mathbf{1 p}$ was partly reduced under the applied reaction conditions, and $\mathbf{1 p}$ gave a mixture of $\mathbf{3 p}$ ' and $\mathbf{3 p}$ '”.

The counteranion of the sulfonium salts is not limited to triflate: $\left[\mathrm{BF}_{4}\right]^{-},\left[\mathrm{PF}_{6}\right]^{-}$, or $\left[\mathrm{SbF}_{6}\right]^{-}$salts of $\mathbf{1 q}$ showed similar Scheme 4. Scope of the Catalytic Zincation of Arylsulfonium Salts. ${ }^{a}$
Scope with respect to aryl substituents

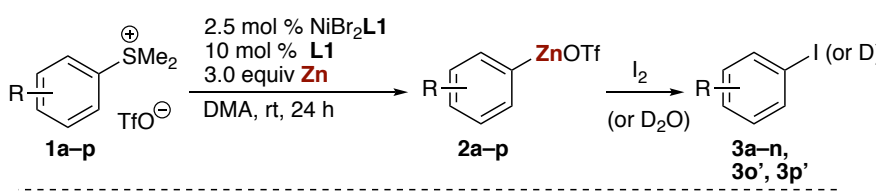

$\overbrace{\mathrm{BeO}^{\prime}}^{\prime}$

3a $84 \%$

3b $59 \%$

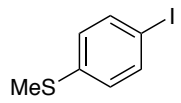

3c $62 \%$<smiles>COc1ccccc1I</smiles>

3d $76 \%$

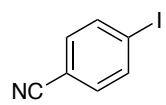

3e $45 \%{ }^{b}$<smiles>COC(=O)c1ccc(I)cc1</smiles><smiles>CC(=O)c1ccc(I)cc1</smiles><smiles>COC(=O)Cc1ccc(I)cc1</smiles><smiles>Ic1ccc2ccccc2c1</smiles>

3i $86 \%$<smiles>Oc1ccc(I)cc1</smiles>

3j $66 \%^{c}$<smiles>COc1ccc(I)cc1</smiles>

3k $81 \%{ }^{c}$<smiles>Clc1ccc(I)cc1</smiles>

31 $76 \%{ }^{c}$ $(90 \%$ NMR)<smiles>Oc1cccc(I)c1</smiles>

OTs

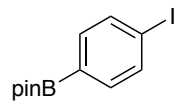

3n $52 \%$ (74\% NMR)<smiles>[2H]c1ccc(OCC(C)(C)Cl)cc1</smiles>

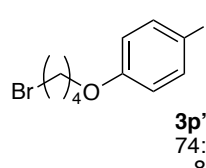

$74: 26$,

. $26,51 \%$ combined NMR yield 89\%D (at phenyl in 3p' and 3p") $31 \% \mathrm{D}$ (for the replacement of $\mathrm{Br}$ in $3 \mathrm{p}$ ") reactivity. It should be noted here that accordingly, the arylzinc species generated from these salts should formally contain a $\left[\mathrm{BF}_{4}\right]^{-},\left[\mathrm{PF}_{6}\right]^{-}$, or $\left[\mathrm{SbF}_{6}\right]^{-}$counteranion and would hence need further investigations from the viewpoint of coordination chemistry. Regarding the substituents on the cationic sulfur atom, dimethyl substituents would be the best in terms of reactivity, selectivity, atom-economy, and ease of preparation. When cyclic sulfonium salt $\mathbf{1}$ b' was used, the zincation proceeded to afford $\mathbf{3 b}$ in $55 \%$ yield. Interestingly, unsymmetrically substituted diarylsulfonium salts $1 \mathbf{r}$ underwent preferential zincation at the most electron-deficient $\mathrm{C}-\mathrm{S}$ bond to yield 3r. Starting from the parent aryl methyl sulfide, the zincation can be implemented in a one-pot procedure after simply removing volatiles upon completion of the methylation with methyl triflate.
Counteranions

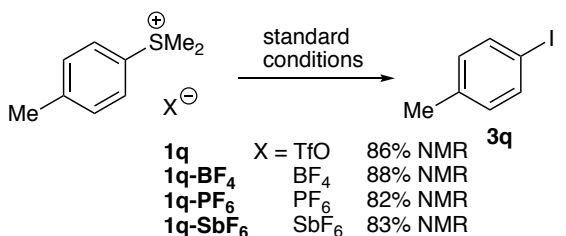

Sulfonium substituents
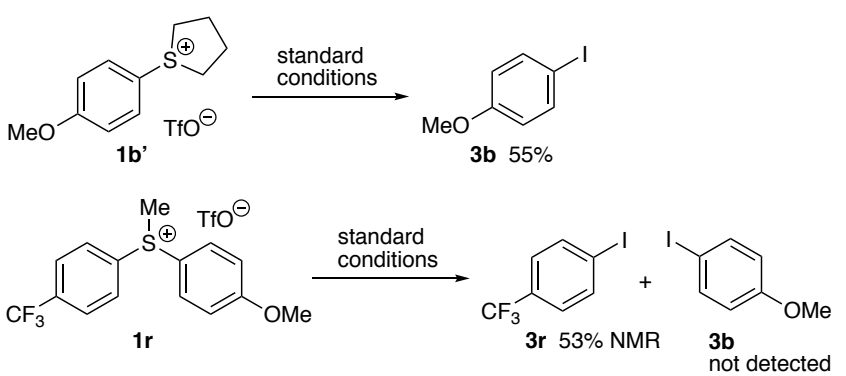

One-pot zincation from sulfide

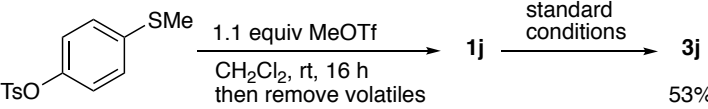

${ }^{a}$ Unless otherwise noted, isolated yields of $\mathbf{3}$ obtained from the arylsulfonium salts are shown. ${ }^{b} p$-Methylsulfanylbenzonitrile was formed in $9 \%$ NMR yield. ${ }^{c} o$-Diiodobenzene was formed in $7 \%$ yield with $\mathbf{3 j}$ and in $<5 \%$ yield with $\mathbf{3 k}$ and $\mathbf{3 1}$.

The behavior of the arylzinc species depends on the counteranion, solvent, and other coexisting reaction components. ${ }^{27}$ In our case, dimethyl sulfide can act as a catalyst poison. Furthermore, nothing was known about the reactivity of the 'accompanying salt-free arylzinc triflates ${ }^{28}$ except for their propensity to undergo iodonolysis. ${ }^{5 \mathrm{~d}, 7}$ We thus investigated the reactivity of our arylzinc triflates, prepared from the sulfonium salts, with transition-metal complexes. Gratifyingly, the onepot Negishi cross-coupling reaction of arylzinc triflate $\mathbf{2} \mathbf{b}$ with 5-trifluoromethyl-2-bromopyridine proceeded smoothly to yield $4 \mathbf{a}$ in $78 \%$ yield (Scheme 5). ${ }^{29}$ In addition, arylzinc triflate 1a underwent a copper-mediated coupling ${ }^{3 e, 30}$ with an acyl chloride. Heteroarylsulfonium salts $\mathbf{1 s}^{31}$ and $\mathbf{1 t}^{32}$ also successfully underwent the zincation followed by a subsequent copper-mediated coupling with an allylic bromide.
It is worth noting that we could, after removing the remaining zing powder by filtration, store the arylzinc reagents under an inert atmosphere and use them efficiently for further cross-coupling reactions (Scheme 6). Stock solutions of $\mathbf{2 a}$ and $\mathbf{2 h}$ were stable at ambient temperature for a few weeks without significant degradation (2a: $0.181 \mathrm{M}$ on April 4th, 2020; $0.165 \mathrm{M}$ on June 1st, 2020. 2h: 0.187 M on June 4th, 2020' 0.178 M on June 17th, 2020).

\section{Scheme 5. One-pot Zincation/Cross-coupling.}



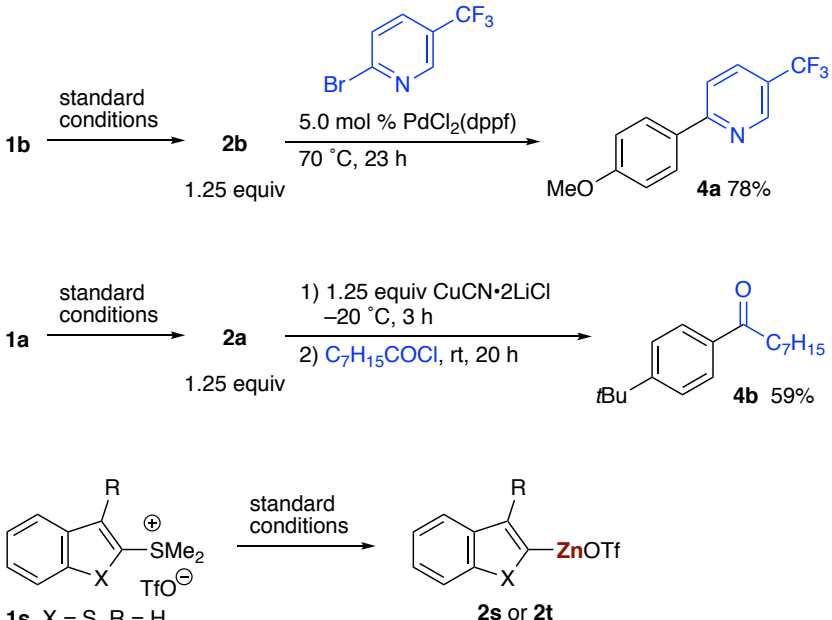

1s $X=S, R=H$

1.25 equiv
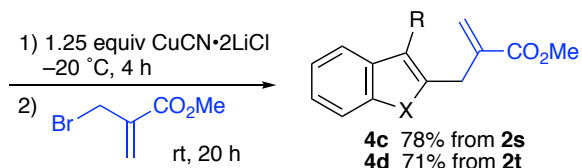

Scheme 6. Cross-coupling Reactions with Arylzinc Stock Solutions.
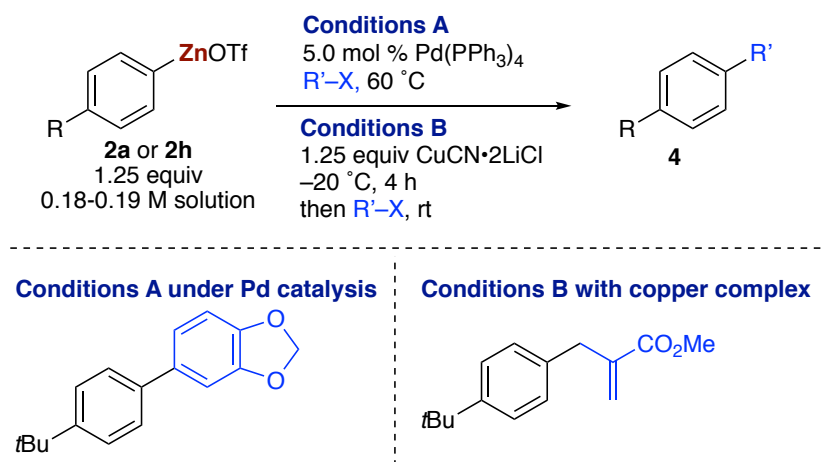

4e $90 \%$ from R'-Br for $24 \mathrm{~h}$

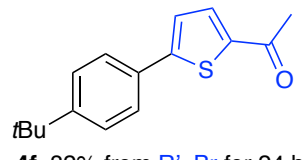

4f $82 \%$ from $\mathrm{R}$ '- $\mathrm{Br}$ for $24 \mathrm{~h}$

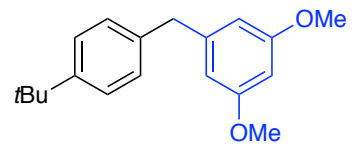

4g $97 \%$ from R'-Br for $24 \mathrm{~h}$

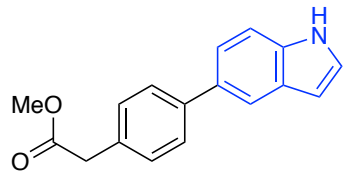

4h $65 \%$ from R'-I for $48 \mathrm{~h}$
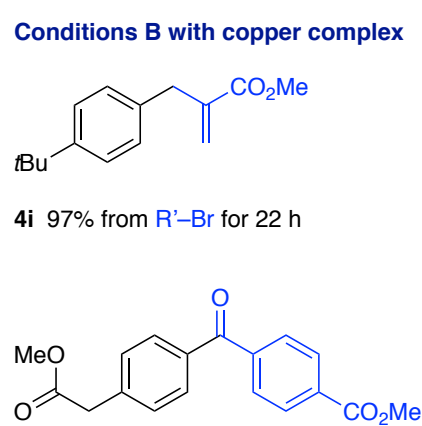

4j $58 \%$ from R'-Cl for $15 \mathrm{~h}$

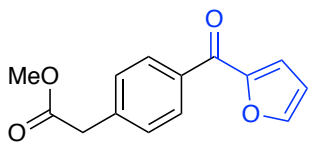

4k $57 \%$ from $\mathrm{R}^{\prime}-\mathrm{Cl}$ for $15 \mathrm{~h}$ 4i $97 \%$ from R'-Br for $22 \mathrm{~h}$

In conclusion, we have demonstrated a highly effective method for the mild preparation of arylzinc triflates by developing a Ni-catalyzed insertion of zinc into the $\mathrm{sp}^{2}$-hybridized $\mathrm{C}-\mathrm{S}$ bond of arylsulfonium salts. Sulfonium salts are readily

available from their corresponding aryl methyl sulfides and methyl triflate. This zincation has thus paved the way to use a wide range of aromatic sulfides via the cleavage of their chemically indolent $\mathrm{C}-\mathrm{S}$ bonds. The zinc insertion takes place with superb chemoselectivity and offers a protocol that is complementary or orthogonal to existing methods for the generation of arylzinc reagents. The prepared arylzinc reagents exhibit consistent reactivity in palladium-catalyzed and copper-mediated cross-coupling reactions. This new zincation can be expected to find applications in the synthesis of bioactive compounds and functional $\pi$-conjugated materials as other known zincation methods have done previously.

\section{AUTHOR INFORMATION}

\section{Corresponding Author}

*yori@kuchem.kyoto-u.ac.jp

\section{Supporting Information}

Experimental procedures and spectral data (PDF). This material is available free of charge via the Internet at http://pubs.acs.org.

\section{ACKNOWLEDGMENTS}

This work was supported by JSPS KAKENHI Grant Number JP19H00895 as well as JST CREST Grant Number JPMJCR19R4. T.Y. gratefully acknowledges the JSPS for a predoctoral fellowship.

\section{REFERENCES}

(1) (a) Organozinc Reagents: A Practical Approach; Knochel, P., Jones, P., Eds.; Oxford University Press: Oxford, 1999. (b) The Chemistry of Organozinc Compounds; Rappoport, Z., Marek, I., Eds.; Wiley: Chichester, 2006. (c) Nakamura, E. in Organometallics in Synthesis, A Manual; Schlosser, M., Ed.; Wiley: Chichester, 2002, Chapter 5. (d) Knochel, P. in Organometallics in Synthesis, Third Manual; Schlosser, M., Ed.; Wiley: Chichester, 2013, Chapter 2.3. (e) Erdik, E. Transition Metal Catalyzed Reactions of Organozinc Reagents. Tetrahedron 1992, 48, 9577-9648. (f) Knochel, P.; Perea, J. J. A.; Jones, P. Organozinc Mediated Reactions. Tetrahedron 1998, 54, 8275-8319. (g) Phapale, V. B.; Cardenas, D. J. Nickel-catalysed Negishi Cross-coupling Reactions: Scope and Mechanisms. Chem. Soc. Rev. 2009, 38, 1598-1607. (h) Valente, C.; Belowich, M. E.; Hadei, N.; Organ, M. G. Pd-PEPPSI Complexes and the Negishi Reaction. Eur. J. Org. Chem. 2010, 38, 4343-4354. (i) Haas, D.; Hammann, J. M.; Greiner, R.; Knochel, P. Recent Developments in Negishi Cross-Coupling Reactions. ACS Catal. 2016, 6, 1540-1552. (j) Dilman, A. D.; Levin, V. V. Advances in the chemistry of organozinc reagents. Tetrahedron Lett. 2016, 57, 3986-3992. (k) Soai, K.; Niwa, S. Enantioselective Addition of Organozinc Reagents to Aldehydes. Chem. Rev. 1992, 92, 833-856. (1) Pu, L.; Yu, H.-B. Catalytic Asymmetric Organozinc Additions to Carbonyl Compounds. Chem. Rev. 2001, 101, 757-824. (m) Yamada, K.; Tomioka, K. Copper-catalyzed Asymmetric Alkylation of Imines with Dialkylzinc and Related Reactions. Chem. Rev. 2008, 108, 1874-1886. (n) Murakami, K.; Yorimitsu, H. Recent advances in transition-metalcatalyzed intermolecular carbomagnesiation and carbozincation. Beilstein J. Org. Chem. 2013, 9, 278-302.

(2) (a) Knochel, P.; Leuser, H.; Gong, L.-Z.; Perrone, S.; Kneisel, F. F. in Handbook of Functionalized Organometallics; Knochel, P., Ed.; WILEY-VCH: Weinheim, 2005, Chapter 7. (b) Knochel, P.; Singer, R. D. Preparation and Reactions of Polyfunctional Organozinc Reagents in Organic Synthesis. Chem. Rev. 1993, 93, 2117-2188. (c) Benischke, A. D.; Ellwart, M.; Becker, M. R.; Knochel, P. Polyfunctional Zinc and Magnesium Organometallics for Organic Synthesis: Some Perspectives. Synthesis 2016, 48, 1101-1107.

(3) (a) Zhu, L.; Wehmeyer, R. M.; Rieke, R. D. The Direct Formation of Functionalized Alkyl(aryl)zinc Halides by Oxidative Addition of Highly Reactive Zinc with Organic Halides and Their Reactions with Acid Chlorides, $\alpha, \beta$-Unsaturated Ketones, and Allylic, Aryl, and Vinyl Halides. J. Org. Chem. 1991, 56, 1445-1453. (b) Guijarro, A.; 
Rosenberg, D. M.; Rieke, R. D. The Reaction of Active Zinc with Organic Bromides. J. Am. Chem. Soc. 1999, 121, 4155-4167. (c) Rieke, R. D.; Hanson, M. V. New Organometallic Reagents Using Highly Reactive Metals. Tetrahedron 1997, 53, 1925-1956. (d) Rieke, R. D. The Reaction of Active Zinc with Organic Bromides. Aldrichim. Acta 2000, 33, 52-60. (e) Knochel, P.; Yeh, M. C. P.; Berk, S. C.; Talbert, J. Synthesis and Reactivity toward Acyl Chlorides and Enones of the New Highly Functionalized Copper Reagents $\mathrm{RCu}(\mathrm{CN}) \mathrm{ZnI}$. J. Org. Chem. 1988, 53, 2390-2392. (f) Picotin G.; Miginiac, P. Activation du Zinc par le Triméthylchlorosilane: Préparation d'Alcools $\beta$-Ethyléniques à Partie de Bromures $\alpha$-Ethyléniques, de Dérivés Carbonylés et de Zinc dans l'Ether. Tetrahedron Lett. 1987, 28, 4551-4552. (g) Gaudemar, M. Sur la Substitution du Zinc au Magnésium dans la Réaction de Grignard. Bull. Chim. Soc. Fr. 1962, 9, 974-987.

(4) (a) Krasovskiy, A.; Malakhov, V.; Gavryushin, A.; Knochel, P. Efficient Synthesis of Functionalized Organozinc Compounds by the Direct Insertion of Zinc into Organic Iodides and Bromides. Angew. Chem., Int. Ed. 2006, 45, 6040-6044. (b) Boudet, N.; Sase, S.; Sinha, P.; Liu, C.-Y.; Krasovskiy, A.; Knochel, P. Directed Ortho Insertion (DoI): A New Approach to Functionalized Aryl and Heteroaryl Zinc Reagents. J. Am. Chem. Soc. 2007, 129, 12358-12359. (c) Metzger, A.; Schade, M. A.; Knochel, P. LiCl-Mediated Preparation of Highly Functionalized Benzylic Zinc Chlorides. Org. Lett. 2008, 10, 1107-1110. (d) Metzger, A.; Schade, M. A.; Manolikakes, G.; Knochel, P. A General Preparation of Polyfunctional Benzylic Zinc Organometallic Compounds. Chem.-Asian J. 2008, 3, 1678-1691.

(5) (a) Fillon, H.; Gosmini, C.; Périchon, J. New Chemical Synthesis of Functionalized Arylzinc Compounds from Aromatic or Thienyl Bromides under Mild Conditions Using a Simple Cobalt Catalyst and Zinc Dust. J. Am. Chem. Soc. 2003, 125, 3867-3870. (b) Kazmierski, I.; Gosmini, C.; Paris, J.-M.; Périchon, J. New progress in the cobalt-catalysed synthesis of aromatic organozinc compounds by reduction of aromatic halides by zinc dust. Tetrahedron Lett. 2003, 44, 6417-6420. (c) Gosmini, C.; Amatore, M.; Claudel, S.; Périchon, J. New Efficient Preparation of Functionalized Arylzinc or Thienylzinc Compounds from Aryl or Thienyl Chlorides Using Cobalt Catalysis. Synlett 2005, 2171-2174. (d) Kazmierski, I.; Gosmini, C.; Paris, J.-M.; Périchon, J. 2,2'-Bipyridine: An Efficient Ligand in the Cobalt-Catalyzed Synthesis of Organozinc Reagents from Aryl Chlorides and Sulfonates. Synlett 2006, 881-884. (e) Bourne-Branchu, Y.; Moncomble, A.; Corpet, M.; Danoun, G.; Gosmini, C. Cobalt-Catalyzed Oxidative Homocoupling of Arylzinc Species. Synthesis 2016, 48, 3352-3356. (f) Linke, S.; Manolikakès, S. M.; Auffrant, A.; Gosmini, C. Cobalt-Catalyzed Formation of 2-Pyridylzinc Reagents and Their Subsequent Coupling. Synthesis 2018, 50, 2595-2600. (g) Dorval, C.; Dubois, E.; Bourne-Branchu, Y.; Gosmini, C.; Danoun, G. Sequential Organozinc Formation and Negishi Cross-Coupling of Amides Catalysed by Cobalt Salt. $A d v$. Synth. Catal. 2019, 361, 1777-1780.

(6) Jin, M.-Y.; Yoshikai, N. Cobalt-Xantphos-Catalyzed, LiCl-Mediated Preparation of Arylzinc Reagents from Aryl Iodides, Bromides, and Chlorides. J. Org. Chem. 2011, 76, 1972-1978.

(7) Klein, P.; Lechner, V. D.; Schimmel, T.; Hintermann, L. Generation of Organozinc Reagents by Nickel Diazadiene Complex Catalyzed Zinc Insertion into Aryl Sulfonates. Chem.-Eur. J. 2020, 26, 176-180. (8) (a) Takai, K.; Kakiuchi, T.; Kataoka, Y.; Utimoto, K. A Novel Catalytic Effect of Lead on the Reduction of a Zinc Carbenoid with Zinc Metal Leading to a Geminal Dizinc Compound. Acceleration of the Wittig-Type Olefination with the $\mathrm{RCHX}_{2}-\mathrm{TiCl}_{4}$-Zn Systems by Addition of Lead. J. Org. Chem. 1994, 59, 2668-2670. (b) Takai, K. Trace Amounts of Second Metal Elements Can Play a Key Role in the Generation of Organometallic Compounds. Bull. Chem. Soc. Jpn. 2015, 88, 1511-1529. (c) Casotti, G.; Iuliano, A.; Carpita, A. Arylzinc Halides by Silver Catalyzed Zinc Insertion into Aryl Iodides. Eur. J. Org. Chem 2019, 1021-1026. (d) Kang, K.; Huang, L.; Weix, D. J. Sulfonate Versus Sulfonate: Nickel and Palladium Multimetallic Cross-Electrophile Coupling of Aryl Triflates with Aryl Tosylates. J. Am. Chem. Soc. 2020, 142, 10634-10640.

(9) For nickel- or cobalt-catalyzed electrochemical syntheses of organozinc compounds using a sacrificial zinc anode, see: (a) Seka, S.; Buriez, O.; Nédélec, J.-Y.; Périchon, J. Mechanism of the Electrochemical Conversion of Aryl Halides to Arylzinc Compounds by Cobalt
Catalysis in DMF/Pyridine. Chem.-Eur. J. 2002, 8, 2534-2538. (b) Gosmini, C.; Rollin, Y.; Nédélec, J.-Y.; Périchon, J. New Efficient Preparation of Arylzinc Compounds from Aryl Halides Using Cobalt Catalysis and Sacrificial Anode Process. J. Org. Chem. 2000, 65, 6024 6026. (c) Conan, A.; Sibille, S.; Périchon, J. Metal Exchange between an Electrogenerated Organonickel Species and Zinc Halide: Application to an Electrochemical, Nickel-Catalyzed Reformatsky Reaction. $J$. Org. Chem. 1991, 56, 2018-2024. (d) Sibille, S.; Ratovelomanana, V.; Périchon, J. Electrochemical Conversion of Functionalised Aryl Chlorides and Bromides to Arylzinc Species. J. Chem. Soc., Chem. Commun. 1992, 283-284.

(10) (a) Sulfur Chemistry; Jiang, X., Ed.; Springer: Cham, 2019. (b) Organosulfur Chemistry I and II; Page, P. C. B., Ed.; Springer: Heidelberg, 1999. (c) Sulfur Reagents in Organic Synthesis; Metzner, P., Thuillier, A., Eds.; Academic Press: London, 1994. (d) Sulfur Compounds: Advances in Research and Application; Acton, A. Q., Ed.; Scholarly Eds.: Atlanta, GA, 2012. (e) Feng, M.; Tang, B.; Liang, S. H.; Jiang, X. Sulfur Containing Scaffolds in Drugs: Synthesis and Application in Medicinal Chemistry. Curr. Top. Med. Chem. 2016, 16, 1200-1216.

(11) Begouin, J.-M.; Rivard, M.; Gosmini, C. Cobalt-catalyzed C-SMe bond activation of heteroaromatic thioethers. Chem. Commun. 2010, 5972-5974.

(12) In our hand, the zincation reaction of methyl tolyl sulfide under Hintermann's conditions proceeded in $25 \%$ yield (iodolysis) while that of methyl 2-naphthyl sulfide was reproducible.

(13) For recent reviews on catalytic C-S-bond transformations, see: (a) Wang, L.; He, W.; Yu, Z. Transition-metal mediated carbon-sulfur bond activation and transformations. Chem. Soc. Rev. 2013, 42, 599-621. (b) Lou, J.; Wang, Q.; Wu, P.; Wang, H.; Zhou, Y.-G.; Yu, $Z$. Transition-metal mediated carbon-sulfur bond activation and transformations: an update. Chem. Soc. Rev. 2020, 49, 4307-4359. (c) Beletskaya, I. P.; Ananikov, V. P. Transition-Metal-Catalyzed C-S, C-Se, and $\mathrm{C}-\mathrm{Te}$ Bond Formation via Cross-Coupling and Atom-Economic Addition Reactions. Chem. Rev. 2011, 111, 1596-1636. (d) Modha, S. G.; Mehta, V. P.; van der Eycken, E. V. Transition metal-catalyzed $\mathrm{C}-\mathrm{C}$ bond formation via $\mathrm{C}-\mathrm{S}$ bond cleavage: an overview. Chem. Soc. Rev. 2013, 42, 5042-5055. (e) Pan, F.; Shi, Z. J. Recent Advances in Transition-Metal-Catalyzed $\mathrm{C}-\mathrm{S}$ Activation: From Thioester to (Hetero)aryl Thioether. ACS Catal. 2014, 4, 280-288. (f) Yorimitsu, H.; Vasu, D.; Bhanuchandra, M.; Murakami, K.; Osuka, Aromatic Metamorphosis of Dibenzothiophenes. Synlett 2016, 27, 1765-1774. (g) Gao, K.; Otsuka, S.; Baralle, A.; Nogi, K.; Yorimitsu, H.; Osuka, A. Cross-coupling of Aryl Sulfides Powered by $N$-Heterocyclic Carbene Ligands. J. Synth. Org. Chem., Jpn. 2016, 74, 1119-1127. (h) Ortgies, D. H.; Hassanpour, A.; Chen, F.; Woo, S.; Forgione, P. Desulfination as an Emerging Strategy in Palladium-Catalyzed C-C Coupling Reactions. Eur. J. Org. Chem. 2016, 2016, 408-425. (i) Kodama, T.; Chatani, N.; Tobisu, M. Catalytic Synthesis of Heterocycles via the Cleavage of Carbon-Heteroatom Bonds. J. Synth. Org. Chem., Jpn. 2018, 76, 1185-1196. (j) Otsuka, S.; Nogi, K.; Yorimitsu, H. C-S Bond Activation. Top. Curr. Chem. 2018, 376, 13. (k) Hirschbeck, V.; Gehrtz, P. H.; Fleischer, I. Metal-Catalyzed Synthesis and Use of Thioesters: Recent Developments. Chem.-Eur. J. 2018, 24, 7092-7107. (1) Takahashi F.; Nogi, K.; Yorimitsu, H. Catalytic inter- and intramolecular coupling of aryl sulfones. Phosphorus Sulfur Relat. Elem. 2019, 194, 742-745. (m) Nogi, K.; Yorimitsu, H. Catalytic Carbonylation and Carboxylation of Organosulfur Compounds via $\mathrm{C}-\mathrm{S}$ cleavage. Chem.Asian J. 2020, 15, 441-449.

(14) For selected recent examples from our group, see: (a) Minami, H.; Otsuka, S.; Nogi, K.; Yorimitsu, H. Palladium-Catalyzed Borylation of Aryl Sulfoniums with Diborons. ACS Catal. 2018, 8, 579-583. (b) Yoshida, Y.; Otsuka, S.; Nogi, K.; Yorimitsu, H. Palladium-Catalyzed Amination of Aryl Sulfoxides. Org. Lett. 2018, 20, 1134-1137. (c) Uno, D.; Minami, H.; Otsuka, S.; Nogi, K.; Yorimitsu, H. Palladium-Catalyzed Mizoroki-Heck-Type Alkenylation of Monoaryldialkylsulfoniums. Chem.-Asian J. 2018, 13, 2397-2400. (d) Takahashi, F.; Nogi, K.; Yorimitsu, H. Intramolecular Desulfitative Coupling: Nickel-Catalyzed Transformation of Diaryl Sulfones into Biaryls via Extrusion of $\mathrm{SO}_{2}$. Org. Lett. 2018, 20, 6601-6605. (e) Otsuka, S.; Nogi, K.; Rovis, 
T.; Yorimitsu, H. Photoredox-Catalyzed Alkenylation of Benzylsulfonium Salts. Chem.-Asian J. 2019, 14, 532-536. (f) Pratap, R.; Yorimitsu, H. Palladium-Catalyzed Amination of Aryl Sulfides and Sulfoxides with Azaarylamines of Poor Nucleophilicity. Synthesis 2019, 51, 2705-2712. (g) Minami, H.; Nogi, K.; Yorimitsu, H. Palladium-Catalyzed Alkoxycarbonylation of Arylsulfoniums. Org. Lett. 2019, 21 , 2518-2522. (h) Uno, D.; Nogi, K.; Yorimitsu, H. Palladium-Catalyzed Arylthiolation of Alkynes Enabled by Surmounting Competitive Dimerization of Alkynes. Org. Lett. 2019, 21, 8295-8299. (i) Fukuda, J.; Nogi, K.; Yorimitsu, H. Cross-Coupling of Aryl Trifluoromethyl Sulfones with Arylboronates by Cooperative Palladium/Rhodium Catalysis. Org. Lett. 2019, 21, 8987-8991. (j) Minami, H.; Nogi, K.; Yorimitsu, H. Nickel-Catalyzed Negishi-Type Arylation of Trialkylsulfonium Salts. Synlett 2020, 31, in press, DOI: 10.1055/s-0040-1707817. (15) For selected recent examples from other groups, see: (a) Ariki, Z. T.; Maekawa, Y.; Nambo, M.; Crudden, C. M. Preparation of Quaternary Centers via Nickel-Catalyzed Suzuki-Miyaura Cross-Coupling of Tertiary Sulfones. J. Am. Chem. Soc. 2018, 140, 78-81. (b) Zhu, D.; Shi, L. Ni-Catalyzed Cross-Coupling of Aryl Thioethers with Alkyl Grignard Reagents via C-S Bond Cleavage. Chem. Commun. 2018, 54, 9313-9316. (c) Ma, Y.; Cammarata, J.; Cornella, J. Ni-Catalyzed Reductive Liebeskind-Srogl Alkylation of Heterocycles. J. Am. Chem. Soc. 2019, 141, 1918-1922. (d) Gong, L.; Sun, H.-B.; Deng, L.-F.; Zhang, X.; Liu, J.; Yang, S.; Niu, D. Ni-Catalyzed Suzuki-Miyaura Cross-Coupling of $\alpha$-Oxo-Vinylsulfones to Prepare $C$-Aryl Glycals and Acyclic Vinyl Ethers. J. Am. Chem. Soc. 2019, 141, 7680-7686. (e) Yim, J. C. H.; Nambo, M.; Tahara, Y.; Crudden, C. M. Copper-Catalyzed Desulfonylative Cross-Coupling of Benzhydryl Sulfones with Azoles. Chem. Lett. 2019, 48, 975-977. (f) Uetake, Y.; Isoda, M.; Niwa, T.; Hosoya, T. Synthesis of (2,2-Diborylvinyl)arenes by Rhodium-Catalyzed Desulfanylative gem-Diborylation of 2-Arylvinyl Sulfides. Org. Lett. 2019, 21, 4933-4938. (g) Chatelain, P.; Sau, A.; Rowley, C. N.; Moran, J. Suzuki-Miyaura Coupling of (Hetero)Aryl Sulfones: Complementary Reactivity Enables Iterative Polyaryl Synthesis. Angew. Chem., Int. Ed. 2019, 58, 14959-14963. (h) Delcaillau, T.; Bismuto, A.; Lian, Z.; Morandi, B. Nickel-Catalyzed Inter- and Intramolecular Aryl Thioether Metathesis by Reversible Arylation. Angew. Chem., Int. Ed. 2020, 59, 2110-2114.

(16) Yanagi, T.; Somerville, R. J.; Nogi, K.; Martin, R.; Yorimitsu, H. $\mathrm{Ni}$-Catalyzed Carboxylation of $\mathrm{C}\left(\mathrm{sp}^{2}\right)-\mathrm{S}$ Bonds with $\mathrm{CO}_{2}$ : Evidence for the Multifaceted Role of Zn. ACS Catal. 2020, 10, 2117-2123.

(17) For selected reviews, see: (a) Cokoja, M.; Bruckmeier, D.-C. C.; Rieger, B.; Herrmannn, W. A.; Kühn, F. E. Transformation of Carbon Dioxide with Homogeneous Transition-Metal Catalysts: A Molecular Solution to a Global Challenge? Angew. Chem., Int. Ed. 2011, 50, 8510-8537. (b) Huang, K.; Sun, C.-L.; Shi, Z.-J. Transition-metal-catalyzed $\mathrm{C}-\mathrm{C}$ bond formation through the fixation of carbon dioxide. Chem. Soc. Rev. 2011, 40, 2435-2452. (c) Tortajada, A.; Juliá-Hernández, F.; Börjesson, M.; Moragas, T.; Martin, R. Transition Metal-Catalyzed Carboxylation Reactions with Carbon Dioxide. Angew. Chem., Int. Ed. 2018, 57, 15948-15982. (d) Burkart, M. D.; Hazari, N.; Tway, C. L.; Zeitler, E. L. Opportunities and Challenges for Catalysis in Carbon Dioxide Utilization. ACS Catal. 2019, 9, 7937-7956.

(18) (a) Everson, D. A.; Jones, B. A.; Weix, D. J. Replacing Conventional Carbon Nucleophiles with Electrophiles: Nickel-Catalyzed Reductive Alkylation of Aryl Bromides and Chlorides. J. Am. Chem. Soc. 2012, 134, 6146-6159. (b) Weix, D. J. Methods and Mechanisms for Cross-Electrophile Coupling of Csp ${ }^{2}$ Halides with Alkyl Electrophiles. Acc. Chem. Res. 2015, 48, 1767-1775. (c) Richmond, E.; Moran, J. Recent Advances in Nickel Catalysis Enabled by Stoichiometric Meta1lic Reducing Agents. Synthesis 2018, 50, 499-513.

(19) Srogl, J.; Allred, G. D.; Liebeskind, L. S. Sulfonium Salts. Participants par Excellence in Metal-Catalyzed Carbon-Carbon Bond-Forming Reactions. J. Am. Chem. Soc. 1997, 119, 12376-12377.

(20) For reviews on cross-coupling reactions of arylsulfonium salts, see: (a) Tian, Z.-Y.; Hu, Y.-T.; Teng, H.-B.; Zhang, C.-P. Application of arylsulfonium salts as arylation reagents. Tetrahedron Lett. 2018, 59, 299-309. (b) Kaiser, D.; Klose, I.; Oost, R.; Neuhaus, J.; Maulide, N. Bond-Forming and -Breaking Reactions at Sulfur(IV): Sulfoxides, Sulfonium Salts, Sulfur Ylides, and Sulfinate Salts. Chem. Rev. 2019, 119,
8701-8780. (c) Kozhushkov, S. I.; Alcarazo, M. Synthetic Applications of Sulfonium Salts. Eur. J. Inorg. Chem. 2020, 2486-2500.

(21) For selected recent examples of the use of arylsulfonium salts, see: (a) Cowper, P.; Jin, Y.; Turton, M. D.; Kociok-Köhn, G.; Lewis, S. E. Azulenesulfonium Salts: Accessible, Stable, and Versatile Reagents for Cross-Coupling. Angew. Chem., Int. Ed. 2016, 55, 2564-2568. (b) Kawashima, H.; Yanagi, T.; Wu, C.-C.; Nogi, K.; Yorimitsu, H. Regioselective $\mathrm{C}-\mathrm{H}$ Sulfanylation of Aryl Sulfoxides by Means of PummererType Activation. Org. Lett. 2017, 19, 4552-4555. (c) Tian, Z.-Y.; Wang, S.-M.; Jia, S.-J.; Song, H.-X.; Zhang, C.-P. Sonogashira Reaction Using Arylsulfonium Salts as Cross-Coupling Partners. Org. Lett. 2017, 19, 5454-5457. (d) Hock, K. J.; Hommelsheim, R.; Mertens, L.; Ho, J.; Nguyem, T. V.; Koening, R. M. Corey-Chaykovsky Reactions of Nitro Styrenes Enable cis-Configured Trifluoromethyl Cyclopropanes. J. Org. Chem. 2017, 82, 8220-8227. (e) Aukland, M. H.; Talbot, F. J. T.; Fernández-Salas, J. A.; Ball, M.; Pulis, A. P.; Procter, D. J. An Interrupted Pummerer/Nickel-Catalyzed Cross-Coupling Sequence. Angew. Chem., Int. Ed. 2018, 57, 9785-9789. (f) Tian, Z.-Y.; Zhang, C.-P. Ullmann-type N-arylation of anilines with alkyl(aryl)sulfonium salts. Chem. Commun. 2019, 55, 11936-11939. (g) Berger, F.; Plutschack, M. B.; Riegger, J.; Yu, W.; Speicher, S.; Ho, M.; Frank, N.; Ritter, T. Site-Selective and Versatile Aromatic $\mathrm{C}-\mathrm{H}$ Functionalization by Thianthrenation. Nature 2019, 567, 223-228. (h) Engl, P. S.; Häring, A. P.; Berger, F.; Berger, G.; Pérez-Bitrián, A.; Ritter, T. C-N CrossCouplings for Site-Selective Late-Stage Diversification via Aryl Sulfonium Salts. J. Am. Chem. Soc. 2019, 141, 13346-13351. (i) Xu, P.; Zhao, D.; Berger, F.; Hamad, A.; Rickmeier, J.; Petzold, R.; Kondratiuk, M.; Bohdan, K.; Ritter, T. Site-Selective Late-Stage Aromatic $\left[{ }^{18} \mathrm{~F}\right]$ Fluorination via Aryl Sulfonium Salts. Angew. Chem., Int. Ed. 2020, 59, 1956-1960. (j) For contributions from our group, see references $13 \mathrm{a}, \mathrm{c}, \mathrm{e}, \mathrm{g}, \mathrm{j}$.

(22) We cannot rule out the possibility of a simple $\mathrm{Ni}^{0}-\mathrm{Ni}^{\mathrm{II}}$ cycle via two very fast single-electron transfers: (a) Rebih, F.; Andreini, M.; Moncomble, A.; Harrison-Marchand, A.; Maddaluno, J.; Durandetti, M. Direct Carboxylation of Aryl Tosylates by $\mathrm{CO}_{2}$ Catalyzed by In situGenerated Ni ${ }^{0}$. Chem.-Eur. J. 2016, 22, 3758-3763. (b) Amatore, C.; Jutand, A. Mottier, L. Mechanism of nickel-catalysed electron transfer activation of aromatic halides: Part 1. Biphenyl electrosynthesis from bromobenzene. J. Electroanal. Chem. 1991, 306, 125-140. (c) Durandetti, M.; Devaud, M.; Périchon, J. Investigation of the reductive coupling of aryl halides and/or ethylchloroacetate electrocatalyzed by the precursor $\mathrm{NiX}_{2}$ (bpy) with $\mathrm{X}^{-}=\mathrm{Cl}^{-}, \mathrm{Br}^{-}$or $\mathrm{MeSO}_{3}{ }^{-}$and bpy $=2,2^{\prime}$-dipyridyl. New J. Chem. 1996, 20, 659-667.

(23) We speculate that an increase in the steric hindrance around the coordinate sites of ligands could enhance stability of the Ni complex and/or promote elimination of dimethyl sulfide by steric repulsion from the metal center. For related research, see: Liu, Y.; Cornella, J.; Martin, R. Ni-Catalyzed Carboxylation of Unactivated Primary Alkyl Bromides and Sulfonates with $\mathrm{CO}_{2}$. J. Am. Chem. Soc. 2014, 136, 11212 11215 .

(24) Beak, P.; Sullivan, T. A. One-Electron Chemical Reductions of Phenylalkylsulfonium Salts. J. Am. Chem. Soc. 1982, 104, 4450-4457. (25) The moderate yields of $\mathbf{3} \mathbf{b}$ and $\mathbf{3} \mathbf{c}$ originated from incomplete conversions.

(26) For unsuccessful examples, see the Supporting Information.

(27) (a) McCann, L. C.; Organ, M. G. On the Remarkably Different Role of Salt in the Cross-Coupling of Arylzincs From That Seen with Alkylzincs. Angew. Chem., Int. Ed. 2014, 53, 4386-4389. (b) HernánGómez, A.; Herd, E.; Hevia, E.; Kennedy, A. R.; Knochel, P.; Koszinowski, K.; Manolikakes, S. M.; Mulvey, R. E.; Schnegelsberg, C. Organozinc Pivalate Reagents: Segregation, Solubility, Stabilization, and Structural Insights. Angew. Chem., Int. Ed. 2014, 53, 2706-2710. (c) Chen, Y.-H.; Ellwart, M.; Malakhov, V.; Knochel, P. Solid Organozinc Pivalates: A New Class of Zinc Organometallics with Greatly Enhanced Air- and Moisture-Stability. Synthesis 2017, 49, 3215-3223. (d) Jin, L.; Liu, C.; Liu, J.; Hu, F.; Lan, Y.; Batsanov, A. S.; Howard, J. A. K.; Marder, T. B.; Lei, A. Revelation of the Difference between Arylzinc Reagents Prepared from Aryl Grignard and Aryllithium Reagents Respectively: Kinetic and Structural Features. J. Am. Chem. Soc. 2009, 131, 16656-16657. (e) Böck, K.; Feil, J. E.; Karaghiosoff, K.; Koszinowski, K. Catalyst Activation, Deactivation, and 
Degradation in Palladium-Mediated Negishi Cross-Coupling Reactions. Chem.-Eur. J. 2015, 21, 5548-5560.

(28) 'Arylzinc triflates' are usually prepared from aryllithium or arylmagnesium reagents and $\mathrm{Zn}(\mathrm{OTf})_{2}$ via transmetalation. Thus, they contain stoichiometric amounts of accompanying salts that may influence the reaction outcome. For examples, see: Johnson, J. B.; Bercot, E. A.; Williams, C. M.; Rovis, T. A Concise Synthesis of Eupomatilones 4, 6, and 7 by Rhodium-Catalyzed Enantioselective Desymmetrization of Cyclic meso Anhydrides with Organozinc Reagents Generated In Situ. Angew. Chem., Int. Ed. 2007, 46, 4514-4518.

(29) Even after several attempts, we failed to use the Ni catalyst in solution for the cross-coupling reactions instead of Pd-based conditions. (30) We used a stoichiometric amount of $\mathrm{CuCN}$ because a catalytic amount of $\mathrm{CuCN}$ led to a significant decrease in yield. For example, treatment of 2a with the allylic bromide in the presence of $10 \mathrm{~mol} \%$ of $\mathrm{CuCN}$ furnished $4 \mathbf{i}$ in only $38 \%$ yield.
(31) Minami, H.; Nogi, K.; Yorimitsu, H. Palladium-catalyzed homocoupling of heteroarylsulfoniums via borylation/Suzuki-Miyaura coupling sequence. Heterocycles 2018, 97, 998-1007.

(32) (a) Murakami, K.; Yorimitsu, H.; Osuka, A. Practical, Modular, and General Synthesis of Benzofurans through Extended Pummerer Annulation/Cross-Coupling Strategy. Angew. Chem., Int. Ed. 2014, 53 , 7510-7513. (b) Murakami, K.; Yorimitsu, H.; Osuka, A. Two-Step, Practical, and Diversity-Oriented Synthesis of Multisubstituted Benzofurans from Phenols through Pummerer Annulation Followed by Cross-coupling. Bull. Chem. Soc. Jpn. 2014, 87, 1349-1366. (c) Hori, M.; Yanagi, T.; Murakami, K.; Yorimitsu, H. Annulative Synthesis of Benzofurans from General Alkenyl Sulfoxides and Phenols via Pummerer/Sigmatropic Cascade. Bull. Chem. Soc. Jpn. 2019, 92, 302-311. (d) Yanagi, T.; Nogi, K.; Yorimitsu, H. Sulfoxide-Directed Iterative Assembly into Oligoarenes. Synlett 2020, 31, 153-157. 
